Fast-Neutron Spectroscopy

By B. V. Rybakov and V. A. Sidorov. Edited by N. A. Vlasov. Translated from the Russian. (Supplement No. 6 of the Soviet Journal of Atomic Energy, 1958.) Pp. ix +121. (New York: Consultants Bureau, Inc.; London: Chapman and Hall, Ltd., 1960.) 17.50 dollars.

$\mathrm{D}$ URING the past few years neutron spectroscopy in the energy-range of $0 \cdot 3-30 \mathrm{MeV}$. has made enormous progress, and in this book we have a review of the field up to 1958. Since this is a Russian work the English translation has not appeared until recently and so is already partly out of date. Nevertheless, it has especial interest because of the coverage it gives of fast-neutron spectroscopy in the U.S.S.R.

The most powerful technique which has been introduced into this field recently is the time-of-flight method. Development of fast pulsed sources and fast detectors and electronic equipment has given this method its present overall usefulness. Approximately two-thirds of the book is given to a valuable discussion of these techniques. The authors have been working with the cyclotron at the U.S.S.R. Institute of Atomic Energy and have considerable experience of time-of-flight work. Their description of this field covers their own equipment and experiments, in addition to others.

There are as well chapters covering methods which have a more specialized application. Such methods as proton-recoil, helium-3 spectrometer and scintillation counter techniques are covered adequately.

This review is intended for people already working in this field or about to do so ; a graduate background of physics is assumed. The style is fair, some clarity and emphasis being lost in translation. However, the actual technical translation errors do not seem to be many. From the aesthetic point of view the cover design is depressing and the print is tiring. Probably most scientists would find it a relatively expensive book.

In conclusion, this book could be recommended as good reading, but searcely worth buying for an individual scientist's library. P. A. Egklstaff

\section{Atomic and Nuclear Physics}

By Prof. Robert S. Shankland. Second edition. Pp. $x v+665$. (New York and London: The Macmillan Company, New York, 1960.) $49 s$.

$\mathrm{T}$

HIS is the second edition of Prof. Shankland's undergraduate text-book. It is cast in the form of fairly brief lecture notes with a minimum of mathematies and perhaps one typical experiment for each topic. The range of physics covered is very broad and admirably up to date. Electron physics, molecular physics, solid state, nuclear and highenergy physics and reactor physies are all included. Although the underlying unity of microscopic physics is implied by including them all in one book, the elear demonstration of this is seriously impeded by the rather traditional and individual presentation of each field. That is, the partial emphasis on historical development is not sufficient to make this aspect very clear, but makes it difficult to see the elegant unity which has been achieved with the help of quantum mechanics.

This is a criticism of the overall organization of the book. The individual topics are treated clearly and simply and in each case carefully selected references to the original literature can lead the student to the details of the work. The experiments described for illustrative purposes are generally very modern ones. About 350 problems are collected at the end of the book.

This text is on the whole a very good example of its kind, especially if accompanied closely by lectures in experimental physics and quantum mechanics.

E. B. PAUL

\section{Mammals of Northern Rhodesia}

A Revised Check List with Keys, Notes on Distribution, Range Maps, and Summaries of Breeding and Ecological Data. By W. F. H Ansell. Pp. xxxi + $180+7$ plates. (Lusaka : Government Printer, 1960.) 12s. $6 d$.

GAR more than a checklist, this is really an admir. I ably produced pocket guide, into which the maximum amount of information has been compressed without losing simplicity of arrangement and ease of reference. With identification keys, notes on habits, habitats and distribution, as well as seven useful colour plates by P. Dandelot, it is a model of its kind. Both the introduction, with its stress on the need for further collecting before the numbers and rang $\epsilon$ of the mammals are irrevocably reduced by human activity, and the discussion of problems of habitat, ecology and distribucion, are well calculated to stimulate or arouse interest in these aspects of the subject. The book will also be of much practical value to the professional working on the mammals of Central Africa. Sections listing rejected species, and species likely to be included as a result of further investigation, help to complete the work, and separate indexes of English, scientific and vernacular names help easy reference.

The only criticism relates to the unfortunate printing of the seventeen full-page distribution maps sideways without a corresponding adjustment of the captions. In two cases, zebra and lechwe, where cross-hatching indicates the distribution of local races, the result is the opposite of what was obviously intended.

R. W. HAYMaN

Remington's Practice of Pharmacy

Edited by Eric W. Martin, E. Fullerton Cook, E. Emerson Leuallen, Arthur Osol, Linwood F. Tice and Clarence T. Van Meter. Twelfth edition. Pp. xii +1866. (Easton, Penn. : Mack Publishing Company, 1961.) n.p.

R. FULLERTON COOK has now played an important part in producing successive editions of this large standard work for more than 60 years. It deals with the whole of American pharmacy from history and ethics to poison control. It contains useful information about all the sciences which a pharmacist must understand, and there are more than 600 pages devoted to the properties of the drugs used in medicine. These drugs are, for the first time, classified pharmacologically, in recognition of the fact that pharmacists are now consulted about the actions of drugs, but a summary of the chemical classification is also included. Among the subjects dealt with in the various parts of the book are statisties, rheology, chromatography, sterilization, methods of manufacture, sustained action medication, aerosols, parasiticides, pesticides, diagnostic drugs, allergenic extracts, radiopharmacy, analytical pharmacy, im. munization and many other things. The information on all these topics is full and up to date. The total 